mitochondria, and minute spines. Usually epidermal cells possess nuclei, secretory granules and endoplasmic reticulum filled within a cell. Most secretory granules are discoidal and circular structured. The integument of the cercaria is quite thinner than that of the adult. The muscle layer which is situated under the fiber layer beneath the integumentary layer, is composed of two layers, the outer layer of circular muscles and the inner layer of longitudinal muscles. The circular and the longitudinal muscles are both the smooth muscles possessing thick and thin myofilaments.

The tail contains the circular muscles which belong to the smooth muscle, and the longitudinal muscles which belong to the striated muscle. The arrangement of the longitudinal muscles of the tail in the cross section appears to possess four muscle groups, five muscle cells in each group.

In the body five pairs of penetration gland cells are distributed, divided into two groups, the anterior two pairs and the posterior three pairs.

\title{
CLINICAL AND LABORATORY FINDINGS IN THE PATIENTS WITH SERIOUS CHRONIC SCHISTOSOMIASIS JAPONICA
}

\author{
Makoto KURATA, MASAJI NOMORI, KōjI MATSUBAYASHI, \\ HIDEHIKO TSUDA AND RYOTOKU NISHIMURA \\ The First Department of Internal Medicine, Kurume University \\ School of Medicine
}

Clinical symptoms as well as clinico-pathological findings have been surveyed in 10 patients with chronic schistosomiasis japonica in a serious grade. In these patients, schistosome eggs could be detected by biopsy of the liver or rectum.

Main clinical symptoms could be numerically summarized as follows; of 10 patients, 6 demonstrated liver swelling, 7 showed spleen swelling, 5 were associated with occurrence of ascites, and 4 were followed by hepatic coma. The skin tests proved to be positive in all 5 cases examined.

Blood examination which was made in 9 cases revealed that hemoglobin content was 60 to $90 \%$ (by Sahli) in 8 cases and less than $60 \%$ in one case, the red cells were counted by $3-5$ million $/ \mathrm{mm}^{3}$ in 6 cases and by $2-3 \mathrm{million} / \mathrm{mm}^{3}$ in 3 cases, and hence the colour index was around 1 in 7 cases, 0.7 in one case and 1.4 in another one case. The number of leucocytes was 4,000 to $8,000 / \mathrm{mm}^{3}$ in 5 cases and less than $4,000 / \mathrm{mm}^{3}$ in 4 . The count of acidophile cells was within the normal extent in 8 cases but was more than $400 / \mathrm{mm}^{3}$ in one case.

Liver functions were also examined. Urinary urobilinogen was positive in 6 out of 9 cases. Latent jaundice (expressing more than 10 units) was recognized in 3 of 8 cases. BSP retention, either slight or moderate, was observed in 9 of 10 cases, Kunkel's test was positive in 7 of 8 cases. In 2 of 7 cases thymol turbidity test proved positive. Cephalin-cholesterol flocculation test represented positive in 5 of 6 cases. Fractionation of serum proteins disclosed that both 
decrease in albumin and increase in gamma-globulin were shown in 8 of 10 cases, the latter being particularly marked. The number of the cases which were followed by a conspicuous decrease in the total amount of cholesterol was 3 of 9 cases. Examination of serum transaminase in 7 cases showed that the activity of the enzyme was slightly increased in $\mathbf{5}$ cases. Alkaline phosphatase activity in serum was also slightly elevated in 2 of 6 cases.

EEG was recorded in 3 cases. In one case which presented hepatoencephalic syndrome, there were irregular slow waves of $2-7 \mathrm{c} / \mathrm{s}$ but the appearance of triphasic waves was not so evident. In another one cases, there were irregular fast waves with lower amplitudes.

No significant change in ECG pattern was present in most patients. When ECG was recorded from the right side wall of the chest and from the left side wall, the number of the patient who demonstrated a lowered ST or T or a reversed $T$ was 1 respectively.

Histologically, the finding to indicate liver cirrhosis was obvious in the liver tissues obtained from 2 autopsy cases and in the liver biopsy specimens taken from 7 cases. One case of the former was complicated by the occurrence of hepatic cancer.

\title{
MORPHOLOGICAL STUDIES ON THE SPERMS OF ANGIOSTRONGYLUS CANTONENSIS
}

\author{
YoshIHITO OTSUJI and TADASHI MAEDA \\ Second Department of Internal Medicine, Kagoshima University School \\ of Medicine, Kagoshima City, Japan
}

In 1935 Chen found Angiostrongylus cantonensis in field mice in Kanton, China. At present it is known that the worm is widely distributed in both tropical and subtropical zones ranging from Southeast Asia to Madagascar.

The larva of the worm, when it is parasitic on the human, usually lives in the brain and it has been known that the parasitism of the worm results in eosinophilic meningo-encephalitis with such abominable symptoms as headache, stiffness of the neck, various sensory disturbances and eosinophilic leucocytosis (eosinophilia) in cerebrospinal fluid. The effective treatment for the disease has not known yet so far though Thiabendazole is said to be a drug worth trying.

The authors of this paper intended to study the mechanism of pharmaceutical action of miscellaneous drugs thought to be effective for Angiostrongylus cantonensis as well as classify parasites based on the morphological features of their sperms.

For that purpose, electronmicroscopic observations on the sperms of Angiostrongylus cantonensis were made as first basic step and the results of the observations were later compared with the results of observations made formerly on the sperms of filarial worms.

The size of male adult worm of Angiostrongylus cantonensis is about $15 \mathrm{~mm}$ - 